\title{
As cartas no Crime de um frade, de José Rodrigues A. Maia
}

\author{
The letters in the Crime de um frade, by José Rodrigues A. Maia
}

\author{
ANA CRISTINA COMANDULLI \\ Universidade Federal do Estado do Rio de Janeiro (UNIRIO). Rio de Janeiro, RJ, Brasil.
} D

\begin{abstract}
Resumo: Leitura do romance de José Rodrigues A. Maia, O crime de um frade, a sua possível leitura em comparação ao Crime do Padre Amaro, de Eça de Queirós. A ligação do autor com o espaço de Alagoas do século XIX diante dos conflitos anticlericais, da sociedade e moralidade. Compreensão da importância da História do atual Estado de Alagoas, desde o Descobrimento até o período em que o livro é escrito, 1895. A ligação Luso-brasileira. Recuperação da memória da literatura e história. Escritores esquecidos que merecem ser recuperados.
\end{abstract}

Palavra-chave: José Rodrigues A. Maia; Alagoas; memória; anticlericalismo; Eça de Queirós.

\begin{abstract}
A Reading of José Rodrigues A. Maia's romance, O crime de um frade, its possible interpretation in comparison to Eça de Queirós' Crime do Padro Amaro. The connection between the author and the XIX century Alagoas' area in front of the anticlerical, societal and moral conflicts. Comprehension of the importance of the History of the current State of Alagoas, from the Discovery to the period in which the book is written, 1895. The LusoBrazilian bonds. Recovery of literature and history's memories. Forgotten writers who deserve to be remembered.
\end{abstract}

Keywords: José Rodrigues A. Maia; Alagoas, memory; anticlericalism; Eça de Queirós.

Ao receber o convite, do CLEPUL, por meio da profa. Vânia Chaves, para participar do Projeto audacioso e complexo Dicionário de Personagens Portuguesas no Romance Brasileiro, imediatamente me pus a ler os livros que me foram atribuídos, tendo em mente que além de uma busca de personagens portugueses, seria necessária uma leitura cuidadosa dos romances brasileiros oitocentista que, via de regra, estão ligados à literatura portuguesa.

Optamos pelo Crime de um frade, de José Rodrigues A. Maia ${ }^{1}$, de quem nada sabemos. A razão primeira foi encontrar personagens portugueses no romance $O$ crime de um frade, de José Rodrigues A. Maia, publicado em 1895. Não havia nenhuma, mas o título me remeteu de imediato ao livro de Eça de Queirós, $O$ crime do Padre Amaro, publicado em 1875. Em nada se pareciam os romances, se imaginarmos o envolvimento amoroso entre o clérigo e a jovem. Em comum está a questão anticlerical, posta em discussão pelos dois autores. $\mathrm{O}$ que poderia ser um só um traço comum acabaria por

\footnotetext{
1 Lamentavelmente não conseguimos ter conhecimento da biografia do autor. Entramos em contato com as Bibliotecas de Alagoas e Pernambuco e não obtivemos retorno.
}

imbricar nossos estudos em uma discussão longa sobre religião em Portugal, cuja discussão estaria entre o berço da Igreja Católica Romana, a Reforma de Lutero (e mais tarde um pouco, a teoria do espiritismo, do Sr. Allan Kardec, ainda no século XIX) e no Brasil, a terra que já constituía mais religiões, a dos indígenas quando os portugueses aportaram no Brasil e mandaram os Jesuítas para catequizálos, a Igreja Americana, a Igreja Luterana, vinda com os suíços, convidados por D. João VI, para povoar a cidade de Nova Friburgo e os movimentos de cunho africano, que hoje construíram marcas em todo nosso território. Mas esse assunto não foi o foco, definitivamente. Ficamos com o rasgo de possibilidade, escancarado por Eça de Queirós, a de apenas denegrir o clérigo vigente, que segundo Eduardo da Cruz e Sérgio Nazar David em análise da EdUERJ, de O crime do Padre Amaro, apontam:

A repercussão no meio literário luso-brasileiro foi enorme. $\mathrm{O}$ anticlericalismo, a crítica social, o combate à escola romântica e o novo modelo da então "escola realista tocaram os leitores e tiveram papel de relevo para que Eça, em sua chegada à cena literária se impusesse (CRUZ; DAVID, 2018, p. 437 e 438). 
Vamos ver também a influência do anticlericalismo português que, em $O$ crime do Padre Amaro, alcançava também o Papa Pio IX (1846-1878), que defendeu, também segundo Cruz e David, dogmas como o da infalibilidade papal e da Imaculada Conceição. Ora, a mocinha da história invoca a sua "santinha" para livrá-la das mãos do comerciante que desejava casar-se com ela:

Nessa tarde, ella ajoelhou-se religiosamente diante do quadro da Virgem e parecia iluminada por uma inspiração celestial.

A fé em certas criaturas é um remédio bastante milagroso para as enfermidades d'alma: é o balsamo celestial que sara as chagas do coração, estancando as lagrimas de desespero que inflamam e amortecem os olhos, assignalando sua passagem com profundos sulcos na face (MAIA, 1859, p. 99).

O anticlericalismo que está ligado nos dois lados do Atlântico, em uma luta em favor de um liberalismo e das ideias de um positivismo que pululavam nos meios acadêmicos. No entanto, no Brasil havia ainda outra luta, a escravagista, como pensa Roberto Schwartz, que reflete em seu texto "As ideias fora de lugar", de 1992. Para Schwartz o ideal do liberalismo chegou em um país, com premissas básicas formando uma ideologia fora de lugar:

Ora, a gravitação cotidiana das idéias e das perspectivas práticas é a matéria imediata e natural da literatura,desde o momento em que as formas fixas tenham perdido a sua vigência para as artes. Portanto, é o ponto de partida também do romance, quanto mais do romance realista. Assim, o que estivemos descrevendo é a feição exata com que a Históriamundial, na forma estruturada e cifrada de seus resultados locais, sempre repostos, passa para dentro da escrita, em que agora influi pela via interna o escritor saiba ou não, queira ou não queira. (...) Ao estudá-lo, vimos que difere do europeu, usando embora o seu vocabulário. Portanto a própria diferença, a comparação e a distância fazem parte de sua definição. Trata-se de uma diferença interna o descentramento de que tanto falamosem que as razões nos aparecem ora nossas, ora alheias, a uma luz ambígua, de efeito incerto (SCWARTZ, 1992, p. 14 e 15$)$.

Antecipamos parte da conclusão: não encontramos um português de papel na Novella Romantica $O$ crime de um frade. O que aponta o romance é um autor brasileiro antenado com a literatura portuguesa e a força dos escritores europeus, principalmente os de França, como Dumas Filho. Não, não encontramos um português no romance de José Rodrigues Maia, mas sim ecos de Eça de Queirós e do pensamento norteador da literatura em Portugal.
Entretanto, pode não ter sido encontrado o português de papel, mas trouxe a possibilidade de (re)apresentar um autor esquecido e, quem sabe, partindo desse pequeno artigo surgir o interesse de pesquisa sobre Rodrigues Maia e outros escritores brasileiros que andam esquecidos em velhas estantes, sebos ou periódicos. Isso partindo do princípio de Walter Benjamin (BENJAMIN, 1994, p. 224) de que uma das etapas do exercício crítico é refletir o seu papel e local na sociedade, e uma outra etapa é a consideração que se deve ter pelo contexto da obra.

Pouco ou quase nada foi possível desvendar de José Rodrigues Maia, autor da "novela romantica" $O$ crime de um frade. Todavia, pautada nos princípios de Gérard Genette (2009) de que os paratextos de uma obra podem esclarecer muito do seu contexto, comecei a análise pelo preâmbulo do livro.

Inicia Rodrigues Maia enviando o seu romance com uma dedicatória à Colônia Alagoana do Rio de Janeiro, reconhecendo-se como um "pobre mestre-escola particular, vivendo ignorado em um obscuro recanto do meu prospero ${ }^{2}$ Estado". No parágrafo seguinte, esclarece, sobre seu texto:

Impressionado por um facto succecedido no interior do nosso Estado, atrevi-me a convertel-o em uma novela, desfigurando-o com outros pormenotres que se entrelaçam no ponto verdadeiro da história, imprimindo-lhe certo caracter mais interessante, como em um painel copiado do natural artista se compraz em colorir com as cores que lhe parecem mais próprias e de maior efeito.

Infelizmente o meu pobre e singelo trabalho não póde merecer a honra da comparação que ahi deixo feita, porque minha intelligencia é bem pobre para adornal-o com as galas preciosas de historia, ataviando-o com essas custosas perolas da Rhethorica que tanto abundam nas grandes mentalidades e nos talentos da primeira agua (MAIA, 1859, p. 6).

Voltando ao texto. Os últimos parágrafos preambulares são palavras de pedidos para reconhecimento de seu trabalho nas letras pelos "ilustres conterraneos", e deixa aos "zoilos"3 - o meu desprezo, deixando-os uivando em

\footnotetext{
2 Acho importante destacar a frase "um obscuro recanto do meu prospero Estado". Por se tratar de um Estado pouco citado ainda hoje no século XXI, que dirá no oitocentos. Essa frase apontava para algo desconhecido para o leitor da época (e de hoje talvez ainda mais). Segundo Eduardo Bueno, em seu livro Brasil: uma história, no século XVI, quando os primeiros europeus chegaram ao litoral alagoano já encontraram os índios tupi, naquele momento voltava da Bahia para Portugal o Bispo Pedro Fernandes Sardinha, tendo seu navio naufragado na costa alagoana, foi Sardinha morto e devorado pelos caetés. Na biografia de Sardinha há o registo de que o fato ocorrido fez com que o sangue do clérigo esterilizasse aquela terra. Esse, seguramente é um dos motivos do esquecimento, haja vista ter ficado marcado pela cultura popular.

3 Zoilos é utilizado no texto como adjetivo para críticos extremos, lembrando que Zoilo foi um filósofo grego conhecido por suas críticas duras e cínicas.
} 
vão á guisa dos rafeiros medrosos que ladram escondidos nas duras sombras as noite" (MAIA, 1859, p. 7). Por meio desse paratexto foi possível perceber que havia algo de muita importância na História do Estado de Alagoas que precisava ser grifado. E isso foi confirmado no decorrer da narrativa.

Oprofessor da Faculdade de História da Universidade Federal de Alagoas, Antonio Filipe Pereira Caetano e também o sítio "História de Alagoas" esclarecem que, em 1839, Maceió foi elevada à condição de Comarca, atingindo o seu apogeu no último quartel do século XIX, mais precisamente em 1895, ano do livro que ora me ocupo. No período de aparente independência com o os estados citados, a barra de Alagoas tornara-se um ponto estratégico para a entrada de "investidores" de outros países, já que esse litoral "permanecia inabitado por portugueses" (FORTES, 2018, p. 34). Fato que pode ser assinalado no romance de Rodrigues Maia ao tratar da descrição dos frequentadores do Club dos Velhos de Nova York como sóbrios e indiferentes (MAIA, 1895, p. 28-29). Mesmo "esquecida", Alagoas chegou a ser uma das primeiras cidades com melhor qualidade de vida do Brasil, em razão de um comércio estrangeiro à Portugal, culminando na facilidade de iluminação por ser um local de fácil extrato do xisto betuminoso. Como esclarecido e descrito no Almanak do Estado de Alagoas para 1894, essas pequenas sedimentares de grão fino encontradas no litoral alagoano, também conhecida como petróleo de xisto, colaborou com a diminuição da utilização do querosene, "que na história de Alagoas fez perecer muitas vidas pelo uso descuidado do combustível".

Definida a urbis, nos parece claro o desejo de Rodrigues Maia em demonstrar um estado com progresso histórico, mas com as deficiências sociais que só a literatura poderia apontar. Esse intuito poderia ser atingido colocando sua obra em uma linha de sociabilidade, preferencialmente já estabelecida fora da cidade natal. Isso pode ser comprovado não apenas pelo encaminhamento do romance à Colônia de Alagoas do Rio de Janeiro, mas também pelo envio de um volume ao Jornal de Recife, na página 2, do número 277, de 1895:

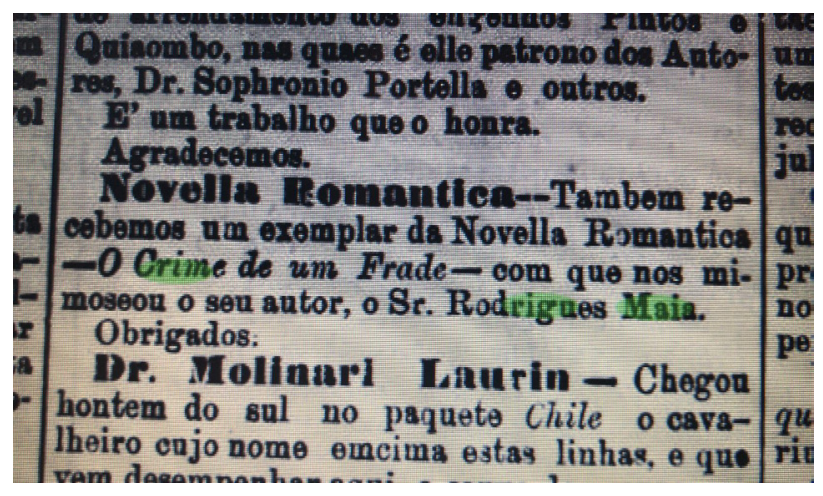

Não parece ser tão difícil entender o enredo do Crime de um frade. Sim, porque ele está ligado, ainda que guardadas as diferenças entre Brasil e Portugal, ao pensamento de enredos entre os romances de Eça de Queirós e o de Maia, por exemplo. Bem modestamente, é possível dizer que Maia teve inspiração em $O$ crime do Padre Amaro ao denegrir a imagem do seu frade, personagem central (ainda que pouco comentada) em seu livro. Assim como a representação literário francesa discutida em Portugal e reproduzida no Brasil. Márcia Abreu no texto "Uma Comunidade Letrada transacional: reação aos romances na Europa e no Brasil”, afirma que:

\begin{abstract}
Um homem de letras que viajasse entre Portugal, França, Inglaterra e Brasil provavelmente perceberia diferenças nas paisagens e na composição étnica das populações, talvez estranhasse a diversidade de comidas e os modos de vestir, mas, certamente, se sentiriam em casa ao conversar com outros eruditos sobre romances em circulação. Não apenas havia grande semelhança entre os livros presentes nos diversos lugares, como também uma forte sintonia nos discursos críticos produzidos a respeito das obras de prosa ficcional (ABREU, 2016, p. 365).
\end{abstract}

Marcia Abreu não alude no seu texto exatamente ao último quartel do século XIX, mas não é errado dizer que a mesma aproximação se aplica ao período do Crime de um frade. Assim como o modelo de narrativa não difere da que lemos em Portugal, como exemplo cartas que se apresentam como narrativa dentro da narrativa maior. Análise semelhante já foi feita por Andreia Castro em sua dissertação de mestrado, defendida em 2010, com o título Amor, desejo e transgressão - as cartas de amor nas novelas camilianas. É o nosso principal foco nesta apresentação, as cartas dentro do romance.

Mas afinal qual é a história a ser contada? Podemos dizer que é de natureza simples. Um viúvo de nome Ambrósio, proprietário de um sítio de tamanho não revelado, mas descrito como o suficiente para ser entendido por terras produtivas e capaz de manter em bom padrão para sua família;para si, sua filha Augusta, a própria irmã, Clara. Limítrofe do sítio de Ambrósio estava localizada a casa de Telêmaco, onde suas filhas recebiam a amiga Augusta para tardes de risos e brincadeiras. Em um desses momentos felizes, o filho de Telêmaco, de nome Alfredo, conheceu a menina Augusta. Paixão imediata.

Alfredo, que então contava vinte e cinco anos, havia saído cedo da casa de seu pai, Telêmaco, para trabalhar na Bahia, onde já tinha adquirido boa situação social. $\mathrm{O}$ jovem tinha recebido ordens médicas de recolher-se em casa dos pais para recuperar-se de um problema de saúde. Ao voltar de sua licença escreveu uma longa carta ao seu amor de longe, dizendo que já não poderia viver sem 
ela. Igualmente, Alfredo escreveu oure missiva ao pai de sua amada. Athanásio, empregado das duas famílias, foi o portador as cartas remetidas para Ambrósio, entregue em mãos à Clara e, com o subterfúgio que requerem os amantes, um bilhete de Amália de Castro, irmã de Alfredo e a carta de Alfredo para Augusta, nos seguintes termos:

\begin{abstract}
Minha adorada Augusta,
É esta a primeira missiva que te escrevo daqui. Fazendo votos d'alma para que estejas feliz, participo-te que estou gozando saude inalteravel. $\mathrm{O}$ ar embalsamado das montanhas entre as quaes vivem nossas familias, a athmosphera pura que ahi respirei, e sobretudo a ventura de ver-te todos os dias e de ouvir-te fallar-me com aquellla voz doce e suave como os acordes de um psalterio, tudo curou-me com uma rapidez que não imaginava! (MAIA, 1895, p. 68).
\end{abstract}

Seguem muitas declarações de afeto e de aproximações de almas, terminando por expor que tinha enviado ao mesmo tempo uma carta ao pai da amada pedindo-a em casamento. E, como sua vaidade e certeza eram grandes, autorizara ao seu pai para receber verbalmente a resposta do futuro sogro.

Por isto acabo de escrever a teu pai, pedindo tua mão. Aguardo ansioso a resposta delle, tendo a vaidade de pensar afirmativamente. Autorisei a meu pai para receber verbalmente a palavra do teu, sobre este assumpto. Qualquer que seja a solução de eu pai, confio que saberás te portar com a fidelidade e com o devotamento que te aconselhar teu virtuoso coração. Adeus, minha Augusta. Aceitas as saudades e o coração onde só tu imperas como rainha, de teu Alfredo de Castro (MAIA, 1895, p. 69).

De forma rocambolesca, o narrador confunde o leitor desatento, propondo ao mesmo tempo três pretendentes para Augusta, que são respectivamente, por entrada na história: Augusto, o Frade e Arthur.

O narrador não aponta ao seu público sobre a importância de uma mulher ser devidamente informada sobre as maldades do mundo, ainda que seja apenas uma sedução, pois "o homem, com instrucção do bem e do mal, além de conhecer o lado fraco da mulher, reconhece essaignorancia dela, e muitas vezes prevalece-se do amor para seduzi-la" (MAIA, 1895, p. 35).

Aparentemente desconhecedora do pensamento do narrador e a respeito do real interesse de Alfredo e, como sabemos, os apaixonados não são silentes,assim a jovem enamorada depositou ao padre da cidade, em forma de confissão, todo o amor que lhe explodia no peito, antes mesmo de receber a cara de seu Alfredo. Dirigiu-se Augusta, como todos da cidade ao encontro semanal com o Senhor na missa celebrada por Frei Pedro, a quem o narrador aponta como sendo um sacerdote "de maus instintos, de alma pervertida pelas paixões mundanas a que se atirava com extravagante deleite", sempre pronto a "iludir os crédulos e incautos" utilizando o confessionário como um "esconderijo, onde se emboscava para atacar a virtude, para ferir o pudor, para preparar a deshonra!..." (MAIA, 1895, p. 41).

Lembramos Carlos Reis, na introdução de sua edição de $O$ crime do Padre Amaro, a gênese do padre, e que, dentro de um campo ideológico são abordadas questões melindrosas como "o poder temporal do clero, a submissão da mulher a esse poder e a instrumentalização da confissão" (REIS, 1989, p.52 e 53). Nas páginas seguintes é Reis também quem afirma que "é um tempo ideologicamente propenso a acentuar a denuncia de desvios e deformações nos agentes e nas práticas religiosas, propensão fundada numa produção intelectual francesa, que tinha em Michelet e Proudhon balizas de referências muito influentes" (REIS, 1989, p. 62 e 63).

Há uma diferença entre os romances de Eça de Queirós e o de Rodrigues Maia. Ainda que ambos tracem uma batalha anticlerical, os dois clérigos se apresentam de formas opostas. Enquanto Eça "aproxima, de modo admirável dois campos semânticos a princípio opostos: o da devoção e do erotismo" (CRUZ; NAZAR, 2018, p.442), Maia mostra o contrário, a falta da devoção, o horror à batina e cultiva, sem qualquer constrangimento, o rebaixamento da utilização de seu cargo de frade no sexo, compreendido apenas como deleite, apenas como pornografia. O frade é descrito como "impuro e de maus instintctos, de alma pervertida pelas paixões mundanas a que se atirava com extravagante deleite (...) sabia mais fazer sacrifícios no altar de Venus que no do Senhor, conde comparecia por mera formalidade e com repugnante hypocrisia" (MAIA, 1895, p. 41). Ao tempo em que ouvia os segredos da jovem, deixava-se envolver na própria volúpia de seus desejos, imediatamente propondo realizar o casamento de Augusta e Alfredo. Marcou hora e lugar para que a moça, pura de coração e corpo, esperasse por seu noivo e um acompanhante de confiança para levá-los ao local onde aconteceria a bênção nupcial.

\footnotetext{
- Nada temas, minha filha. Bem sabes que ninguem te ouve a não ser eu que aqui tenho o poder de representar a Deus, a cujos pés vens depositar confissão.

O confessionário é o consultório do medico d'alma que é o sacerdote a quem todo o peccador recorre para cural-o das doenças do espirito, das enfermidades da consciencia (MAIA, 1895, p. 42).
}

Depois da missa, Frei Pedro dirigiu-se para o sacristão André, que não gozava de muita inteligência, e disse que precisaria de sua ajuda para realizar algo que ouvira em confissão. 
Um corte é dado na história de Augusta. Além de Alfredo, o frade André, o degenerado, havia outro pretendente, Arthur. "Um rapaz de vinte e oito anos que fôra empregado em uma casa comercial em Recife" (MAIA, 1895, p. 58). Era solteiro, morava só e tinha por companhia "um cabrinha de dezenove anos que lhe servia de criado" (ibidem). O desenrolar da figura de Arthur faz lembrar o que entendia Alexandre Dumas Filho, romancista que apresentava a vida conjugal sob um ponto de vista absolutamente material. Muito provavelmente a leitura de Arthur tratava-se de $A$ Dama das Camélias $^{4}$ e também não coincidentemente uma referência à morte do escritor francês ocorrida no mesmo ano da publicação do Crime de um frade. Vale lembrar que Franco Moretti, em seu Atlas do Romance europeu 1800-1900, aponta que a obra de Dumas foi inteiramente traduzida em quase toda Europa ocidental, abrangendo de forma integral a Península Ibérica, consequentemente, chegou ao Brasil.

Voltando ao que Rodrigues Maia escreveu. O romance de Dumas, todavia, leva Arthur a desejar casar-se com a mais exuberante jovem da redondeza, Augusta, como vemos:

No momento em que o apresentamos, ele estava recolhido em sua casa de vivenda, porque os ponteiros de um grande relogio de sua sala indicavam ser dez horas e cinco minutos.

Mettido em um chambre de cretone azul, estava sentado a uma secretaria, e lia distrahidamente um romance de Dumas Filho, com o cotovéllo apoiado sobre a mesa e o queixo na palma da mão.

- Brutaes romancistas! disse ele atirando o livro em cima da mesa.

Apresentam a vida conjugal sob um ponto de vista todo material!

Realmente, apezar das provas philosophicas com que o romancista atavía a obra, dando-lhe um cunho de verdade irrecusável, desejo fazer experiencia. (...) Uma mulher como Augusta satisfaz ao homem mais exigente em materia de beleza e de todos os dotes physicos (MAIA, 1895, p. 59).

Sabedor de que a mulher que escolhera para ser sua já estava com seu coração comprometido, o solteiro até então convicto escreve uma carta anônima ao pai de sua pretendente, incitando-lhe a ira de contra a reputação do jovem pretendente de sua filha. Forjando ser uma carta

\footnotetext{
4 Há registro de um volume no Real Gabinete Português de Leitura, de 1889. Além dessa informação, Bruna Rondinelli, publicou na Revista Miscelânea, em 2013, o texto "A Dama das Camélias desembarca no rio de janeiro: encenações e recepção crítica (1856-1860)", onde afirma que a primeira Jornal das Senhoras. Na Biblioteca Nacional, além de um exemplar do romance de 1860 há também o manuscrito da solicitação de exame censório ao Conservatório Nacional, e o registro do inventário feito pela própria Fundação.
}

enviada da Bahia, o anônimo desqualifica o rival da forma mais vil possível:

$$
\begin{aligned}
& \text { Esse sr. Alfredo é dado aqui á vida desregrada, possue } \\
& \text { amantes e tem em muitopoucaconta a innocencia } \\
& \text { das donzelas, conforme se depreende do facto de um } \\
& \text { defloramento vergonhoso praticado por elle, nesta } \\
& \text { cidade. } \\
& \text { Esses excessos de vida licenciosa causaram-lhe o in- } \\
& \text { commodo que hoje soffre e do qual é difficil curar-se, } \\
& \text { conforme affirmam os medicos (MAIA, 1895, p.60-61). }
\end{aligned}
$$

Recebeu Ambrósio as duas cartas ao mesmo tempo: a de Alfredo e a anônima. Acreditando no impostor, o pai de Augusta não concedeu o pedido de casamento feito pelo filho de Telêmaco, passando a implorar que sua filha cedesse ao pedido de casamento de Arthur, que a essa altura já estava intrometido na casa da família.

Clara, a tia preceptora da jovem, percebendo a possibilidade de uma poderosa armação tratou de colocar o serviçal da fazenda, Athanasio, como um possível colaborador de Arthur a fim de descobrir algo que desabonasse sua conduta. Essa investigação não tardou a ter uma boa solução para revelar o homem infame. Aproveitando uma gripe que deixara Arthur preso ao leito, Athanasio procurou e encontrou uma folha marcada da letra do "anônimo", além de um mata-borrão fabricado caseiramente com o registo dos Correios da Bahia.

Enquanto se desenvolvia os fatos na fazenda da cidade que não é nomeada no romance, Alfredo já sabedor da infame carta sem assinatura, publicou, na imprensa da Bahia, uma carta que desbaratava o caráter maligno do insultador, com o seguinte final:

Sei que quem escreve uma carta anonyma cheia de calumnias, é bastante covarde, á bastante vilão para provar com factos aquella denuncia infamante com que foi alvejada minha honra; porém ahi fica o repto que me cumpria fazer, no intuito de repercutir pela potente voz da imprensa lá pelas plagas do meu torrão natal, onde quiçá a alludida denuncia possa achar echo em espíritos propensos ao mal (MAIA, 1895, p.97).

O pai de Augusta desafiou o desejo da filha e impôs a sua vontade - ela se casaria com Arthur. Alfredo, que havia retornado à casa do pai, teve ciência da falcatrua de seu rival, com aquiescência da jovem resolveu raptá-la. Foi nessa altura de desespero que Augusta correu para igreja e se pôs ao pé do confessionário para desabafar ao representante de Deus na terra o que acontecia.

O Frade André, já mencionado, voltará à cena para raptar a moça. Augusta que esperava por Alfredo acabou por ser raptada pelo frei Pedro. Primeiro entorpecida pelo acólito e colocada na cela de um cavalo, a mocinha começa a recuperar lentamente e pede: "- Alfredo, 
ampara-me, sinto-me entorpecer!" (MAIA, 1895, p. 112), o que o frade respondeu: “- Não temas, minha santa. O rapaz não pode vir, e encarregou-me de levar-te nossa casa. É lá que ele te espera." (ibidem). Augusta volta aos seus sentidos, reconhece o frade e o chama de embusteiro e profano. Mesmo com toda a sua força, a menina não teria conseguido fugir das mãos do herege, não fosse por Athanásio. Tomando conhecimento dos desejos de Alfredo e percebendo que as pessoas que haviam feito o rapto da donzela, Athanásio saiu ao encalço dos devedores de meninas ingênuas, e salvou Augusta do cavalo onde estava com Frei André. O acólito fugiu, sem deixar rastros.

Em retorno ao lar, Ambrósio, finalmente fica sabendo de toda a mixórdia e finalmente autoriza o casamento entre sua filha e Alfredo de Castro. Termina o romance com a realização do enlace matrimonial e a descrição do fim do frade. Esse foi encontrado, dias depois, morto, assim como seu cavalo em uma vala na estrada pela qual fugira.

Está claro desde o início do romance que não houve qualquer intenção de Augusta pelo frade, o seu amor puro e casto só pertencia ao homem para quem guardou o seu coração - Alfredo. A família era conservadora e não permitiria qualquer casamento que não estivesse dentro dos padrões de moral e bons costumes, daí ter Arthur entrado na história para mostrar um lado, ainda que falso, de um bom homem, trabalhador. Logo, a moral construída falsamente seria vencedora já que do outro rapaz tudo o que havia era uma carta anônima que o denegria. A falsidade de um padrão aceitável era superior pelas credenciais apresentadas pessoalmente, uma máscara de benignidade, benevolência, um falso amor para ser apresentado à sociedade. Desmascarado, portanto, "desmoralizado" ao fim do romance. O romance é, sem dúvida, moralista e anticlerical, mas muito mais coisa pode e deve ser discutida em autores desconhecidos como Rodrigues Maia e outros tantos que podemos encontrar e iluminá-los. A História de Alagoas, até onde foi possível procurar saber, segue um fluxo muito peculiar em relação aos movimentos religiosos e políticos no Brasil. É necessário buscar autores brasileiros, com ou sem Portugueses de Papel.

\section{Referências}

ABREU, Marcia. Uma comunidade letrada transnacional: reação aos romances na Europa e no Brasil. In: ABREU, Márcia (Org.). Romances em movimento: a circulação transatlântica dos impressos (1789-1914). Campinas-São Paulo: Editora da Unicamp; FAPESP, 2016. p. 365-394.
Acervo Cartográfico da Biblioteca Nacional. Almanak do Estado de Alagoas para 1894. Maceió: Typ. Da Empreza Gutemberg, 1894.

BARROS, Francisco Reinaldo Amorim de. ABC das Alagoas Dicionário Bibliográfico, Histórico e Geográfico das Alagoas. Brasília: Senado Federal, 2006. 2 v.

BENJAMIN, Walter. Magia e técnica, arte e politica: ensaios sobre literatura e cultura. São Paulo: Brasiliense, 1994.

BUENO, Eduardo. Brasil: uma história. 2. ed. São Paulo: Ática, 2003. p. 19

CAETANO, Antonio Filipe Pereira. "Existe uma Alagoas Colonial?": Notas preliminares sobre os conceitos de uma conquista ultramarina. In: Revista Crítica Histórica, ano I, n. 1, jun. 2010.

CASTRO, Andreia Monteiro Alves de. Amor, desejo e transgressão - as cartas de amor na novela camiliana. Dissertação (Mestrado) - Universidade do Estado do Rio de Janeio (UERJ), 2010. Disponível em: <https://www.historiadealagoas.com.br/ a-saga-do-petroleo-alagoano-i-primordios.html >. Acesso em: 13 out. 2018

CRUZ, Eduardo; DAVID, Sérgio Nazar. O crime do Padre Amaro: um desacabamento catastrófico. In: QUEIRÓS, Eça. O crime do Padre Amaro. Rio de Janeiro: EDUERJ, 2018. p. 447-448.

GENETTE, Gérard. Seuils. Editions du Seuil, 1987.

Jornal de Recife, n. 277, 1895. p. 2.

MAIA, Antônio Rodrigues A. O crime de um frade. Maceió: Typ. Trigueiros \& C., 1895.

MORETTI, Franco. Atlas do romance Europeu (1800-1900). São Paulo: Boitempo Editorial, 2003.

OLIVEIRA, Alexandra Almada de; CHEVALIER, Gabriela de; ROCHA, Quézia Júnia de Moraes (Org.); LEMOS, Valéria Pinto. Os exames Censórios do Conservatório Dramático Brasileiro: Inventário Analítico. Rio de Janeiro: Fundação Biblioteca Nacional, 2014. (Registro no 746).

REIS, Carlos; CUNHA, Maria do Rosário. Introdução. In: QUEIRÓS, Eça. O crime do Padre Amaro (2 $\underline{a}$ e $3^{\underline{a}}$ versões). Lisboa: Imprensa Nacional Casa da Moeda, 2000.

RONDINELLI, Bruna Grasiella da Silva. A Dama das Camélias desembarca no rio de janeiro: encenações e recepção crítica (1856-1860). In: Revista Miscelânea, Assis, v. 14, p. 103-123, 2013.

SCWARTZ, Roberto. As idéias fora do lugar. In: SCWARTZ, Roberto. Ao vencedor as batatas. 4. ed. São Paulo: Duas Cidades, 1992.

Recebido: $17 / 10 / 2018$

Aprovado: 25/11/2018

Autora:

ANA CRISTINA COMANDUlli DA CUNHA

Universidade Federal do Estado do Rio de Janeiro (UNIRIO).

Real Gabinete Português de Leitura (RGPL). Centro de Estudos

Clássicos da Universidade de Lisboa.

ana.comandulli@gmail.com

(D) 0000-0003-2328-5689 